Volume 11(1) (2014), 15-26

Copyright (c) Equinox Publishing Ltd

Sheffield

http://equinoxpub.com

DOI: $10.1558 /$ cam.v11i1.26446

\title{
Treating without diagnosis: Psychoanalysis in medical settings in Argentina
}

\author{
JUAN EDUARDO BONNIN \\ Consejo Nacional de Investigaciones Científicas y Técnicas, Argentina
}

\begin{abstract}
This article is part of a larger research project, the aim of which is to understand the discursive conditions of access and adherence to an outpatient mental health service at a public hospital in Buenos Aires, Argentina. The focus is on the historical conflict between medical discourse and psychoanalytical discourse as it emerges in the negotiation of treatment and diagnostic sequences at first consultations. It can be seen that patients who are socialized in medical discourse - and even in psychiatric discourse - expect the usual procedure in which a diagnosis, however transitory, is offered first and then followed by a treatment recommendation. However, psychoanalysts, in contrast, tend to reject diagnostic labels and offer treatment without further justification. This has an impact on the adherence of patients, and we can argue for the need to negotiate with medical discourse in order to guarantee engagement and continuity in treatment.
\end{abstract}

Keywords: diagnosis; doctor-patient communication; medical discourse; mental health; psychoanalysis; treatment

\section{Introduction}

This article presents the results of research conducted in the domain of language and access to mental health care. Since 2011, I have been conducting ethnographic observations at an outpatient mental health service at a public hospital in Buenos Aires, Argentina (here called 'the Hospital'). The main source of data, in addition to ethnography, consists of audio-recordings of the first consultations of clients who are seeking to be admitted as outpatients to the mental health service. $^{1}$

One of my early ethnographic observations concerned the conflict of expectations between professionals and patients regarding activity that takes place as an 'admission interview'. For the healthcare professionals, it is a 'first consultation', designed to classify patients according to basic psychoanalytic clinical types. If the patient is identified as psychotic, he/she is referred to psychiatry and psychotherapy; if the patient is identified as neurotic, he/she is referred to one of the psychotherapeutic specialties (addictions, eating disorders, family, adults, youth, etc.). ${ }^{2}$ To the patient, however, especially if she/he has not received prior psychoanalytic treatment, the interview is itself a clinical instance: it is conducted by professionals who call him/her a 'patient', who are encountered in a 'consulting room', and who - in many cases - are dressed in a white coat. Indeed, as the first contact with psychologists/psychoanalysts for many patients, first mental health interviews have many features in common with primary care encounters (Heritage and Maynard 2006; Peräkylä et al. 2008) and acute medical visits (Koenig 2011). However, there is a major difference regarding the sequential organization of these interactions: while traditional medical consultation usually presents diagnosis first, followed by treatment recommendations, first consultations 
in psychoanalysis, as observed in my fieldwork, recommend treatment first and do not offer a diagnosis to justify it.

This is the issue I discuss in this paper: the conflict of expectations regarding the activity being conducted by professionals and patients, as observed in the negotiation of diagnostic and treatment sequences during first interviews at an outpatient mental health service at the Hospital.

Below, I argue that the negotiation of diagnostic and treatment sequences in my corpus entails a historical conflict between psychoanalysis and medical institutions. Patients have inadvertently been socialized in medical discourse and expect interaction similar to the highly structured acute visit, which offers a diagnosis and a treatment recommendation. Analysis of this misunderstanding allows us to discuss the impact of this conflict on access to mental health care, arguing for the need for psychoanalysts to negotiate with medical discourse.

First, I begin with some specifics underpinning the historical relationship between psychoanalysis and the mental health care system in Argentina. I then describe, from a synchronic perspective, the conflictual relationship between Lacanian psychoanalysis and the clinical practice of diagnosis. From this viewpoint, analysis of interactions will facilitate our understanding of how these historical and ideological factors impact on the situated professional-patient encounter in public hospitals, thus conditioning the access of patients to their right to mental health.

\section{Psychoanalysis and (public) mental health in Argentina}

Psychoanalysis did not develop early in Argentina. The Argentine Psychoanalytic Association (APA) was not founded until 1942, 32 years after the creation of the International Psychoanalytic Association (IPA) by Sigmund Freud. Argentine medical associations were highly suspicious of the APA during the 1940s and 1950s, and, therefore, kept it out of public hospitals as long as they could (Plotkin 2001); however, although psychoanalysis was not regarded as a legitimate specialty by the medical establishment, it was nevertheless a prestigious and lucrative private practice which was targeted at clients belonging to the higher class (Balán 1992: 114-119).

The late 1950s and early 1960s brought significant change regarding the relationship between psychoanalysis, society and medicine. We can outline two processes which began in those days that can be traced to the present era. First, in 1957, the University of Buenos Aires established a degree program in Psychology. Although the field was reluctant to accept psychoanalysis, and the course was intended for training college graduate assistants to be psychiatrists, non-medical psychologists were also trained and given official recognition for the first time (Balán 1992). Second, during the 1960s, the 'mental health movement' (movimiento de salud mental) was born. This grouped young psychiatrists, who fought against the positivist 'mental hygiene' paradigm that proposed reclusion and medication as the main pathway for the treatment of mental illness (Macchioli 2012). The reformers introduced radically new concepts, combining sanitary, sociological, psychoanalytic and political elements. One of the innovations of the mental health movement was the introduction of psychoanalysis as a new experimental tool for treating mental illness at public hospitals (Lakoff 2006: 75).

This introduction was heterodox not only to old psychiatrists, but also to traditional, Freudian psychoanalysts, for a number of reasons: 'therapy was provided for free, there was no couch, and transference was potentially hampered by the difference in social class between therapist and patient' (Lakoff 2006: 75). Within a highly politicized context, new college-trained psychologists/psychoanalysts began to gain presence in public hospitals as part of a scientific and political movement of mental health workers, which saw psychoanalysis as a powerful tool for social change (Plotkin 2001: 138). As a reaction against Freudian orthodoxy, represented by the APA, new psychoanalysts found in Jacques Lacan (and his rebellious attitude against the IPA) a new mentor to follow for their own intellectual, medical and political project.

Current chiefs of staff at the Hospital were trained during the late 1960s and early 1970s, and 
therefore participated in this militant psychoanalytic movement which brought Lacan to public hospitals in a more or less implicit war against medical psychiatry and traditional psychoanalysis. The confrontation between 'medical' discourse and 'psychoanalytic' discourse at public hospitals is not only asserted by mental health practitioners, but has also been analyzed by social research, as shown in the work of Lakoff (2006).

Although this confrontation is often apparent among healthcare professionals in their words and attitudes towards each other (cf. Lakoff 2003), patients are not usually aware of it. On the contrary, most patients who visit the outpatient mental health service have never received prior psychoanalytical attention. However, they have attended public hospitals since childhood, and are thus used to the clinical encounter and its highly structured sequential organization. In what follows, we observe the conflict and negotiation of diagnostic and treatment sequences as a byproduct of this historical and ideological tension in first interviews at an outpatient mental health service conducted by Lacanian psychoanalysts.

\section{The problem of diagnosis}

Lacanian psychoanalysis, as developed in Argentina, has a conflictual relationship with the practice of diagnosis. There is general consensus on the recognition of three basic clinical types: neurosis, psychosis and perversion (Thompson et al. 2006). However, there has been continuous fluctuation regarding the status of the analyst as a subject of diagnostic knowledge in the therapeutic relationship. Rubistein (1999) states that in the 1970s there was an exaggerated rejection of the analyst's knowledge, considered as a 'subject supposed to know', in Lacanian terms. This 'confusion between referential knowledge and textual knowledge of the unconscious' (Rubistein 1999: 120) ultimately led to serious clinical disorientation, especially in the case of psychosis treatments. Later on, during the 1990s, the intervention of Lacanian psychoanalysts at public hospitals brought back the issue of diagnosis as a clinical need, not only in terms of treatment and therapy for the patient but also in terms of institutional criteria regarding legitimate healthcare practices (Crowe 2000).

Thus, a conflict arose between a psychoanalytical conception of diagnosis as a process conducted by the patient through treatment, and a medical, psychiatric conception, which considers diagnosis as the pre-condition to identifying the illness and treating it to achieve the cure (Thompson et al. 2006: 104). As a consequence, every interview is fraught with this tension between the singularity of the case - which, ultimately, defies the possibility of diagnosing - and the regularity of types as listed on a diagnosis chart provided by the Mental Health Care Department of the City Government. This chart has been developed mainly on the basis of the Diagnostic and Statistical Manual of Mental Disorders (DSM-IV; American Psychiatric Association 1994) and the International Classification of Diseases (CIE-10, World Health Organization 1999). To many professionals, however, this chart is merely a 'neoliberal policy' designed to standardize the psychiatric market and open it to foreign pharmaceutical products (Lakoff 2006: 57).

Although psychoanalysts oppose the use of the DSM-IV at public mental health services in Buenos Aires, it is institutionally mandatory to label every patient interviewed with the code of one of the disorders listed in the form. The professional takes the decision of attributing one diagnostic label or another after completing the interview, simply by reasoning out loud or in conversation with the assistant psychologist or even with the researcher. This process of diagnosing 'properly' is simultaneously discredited yet mandatory - a fiction of clinical work which will later be used for preparing statistics. ${ }^{3}$

\section{Setting and methodology}

Public hospitals, and in particular the one in which I conducted my fieldwork, are overwhelmed by a demand that cannot be met under current human and material conditions. 
The mental health service is overpopulated and short-staffed, and there are currently only five to ten slots available per week for admitting new patients. The purpose of the first interview is thus both to admit some applicants as patients and refer them to specific services (individual therapy, group therapy, addictions, among others), and to reject others. In 2012, 85\% of those who attended a first interview did not go on to receive a course of treatment: $35 \%$ were rejected, while a further $50 \%$ chose not to return (Bonnin 2014). Interviews are thus an important link between the 'outside' and the 'inside' of the mental health service, and performance in the clinical encounter is a major factor in accessing appropriate treatment.

According to statistics prepared by the outpatient mental health service, about $20 \%$ of the patients who attend first interviews require psychiatric care due to a psychopathological condition. The other $80 \%$ receive psychotherapy, specifically psychoanalytic psychotherapy. Nevertheless, $57 \%$ of these patients have never received psychotherapeutic treatment before, which means that they do not know what a psychological/analytical treatment is: curing with words. Neither are they aware of the ambiguous status of diagnosis in psychoanalysis or the fierce criticism of the same professionals regarding DSM-IV and other diagnostic manuals used in the public mental health system.

In what follows I present some results of a larger research project, the aim of which is to understand the discursive conditions of access to mental health care at the Hospital. I carried out ethnographic observations of first interviews at the outpatient mental health service at the Hospital during 2011-2013, recording 81 interviews, after having obtained the written informed consent of professionals and clients. To ensure confidentiality, as well as not identifying the hospital where the interviews took place, I have also replaced the names of patients and professionals with randomly selected letters. The research project was conducted in collaboration with the team of professionals, who cooperated not only with the process of accessing the field and obtaining the data but also with the interpretation of data.
The interviews were of an average duration of 20 minutes, and were held at consulting rooms at the hospital. They were usually conducted by two professionals who interviewed individual patients, although sometimes patients were accompanied by a relative or friend. Although there was not an explicit distribution of roles, usually one of the professionals (the more experienced, though not necessarily the older) took the lead in interviewing while the other simply took notes. I have called the former 'psychologist in charge' (PC) and the latter 'assistant psychologist' (AP) (Bonnin 2013).

The data are analyzed from a discourse analysis perspective developed in Latin America in recent years, thus providing an interdisciplinary approach to our corpus by combining the ideological and historical interest in discourse (Arnoux 2006) with a detailed examination of interaction (Bolívar 2010), especially sequential organization. From this point of view, descriptive concepts provided by conversation analysis (such as sequence, turn, repair) are incorporated to better account for conversational events, without ignoring discourse processes (Blommaert 2005).

\section{Sequencing treatment and diagnosis}

I here analyze conversation during first interviews to identify treatment and diagnosis sequences. As my sampling is not intended to be representative, but, rather, theoretically relevant, I will focus on examples which show the tension between the offer of treatment by professionals and the demand for diagnosis by patients. The analysis will be presented in two stages, as emergent in the interaction. First, we will observe how patients try to negotiate a 'diagnostic label' (Garand et al. 2009) and, complementarily, how professionals dismiss self-diagnosis, either implicitly or explicitly. Secondly, I will draw attention to the offer of treatment by professionals and the strategies displayed by patients to resist or accept it.

Although I illustrate my argument with different examples, I will follow one, the case of R, to demonstrate the articulation of the three stages throughout a single interview. 


\subsection{Dismissing self-diagnosis}

We first turn to the interview with $\mathrm{R}$, a 54-yearold male divorcé currently engaged in a new relationship. He has a small pension and inadequate social insurance, and therefore goes to public hospitals for the services not covered by his insurance. He has been receiving psychiatric outpatient treatment, which he finished four years before the interview, but still selfmedicates with Clonazepan and Sertraline, which he buys on the black market without a prescription.

Although the first part of the interview is devoted to asking institutional questions to complete a statistical standardized form, at this time patients usually present the reasons why they have approached the mental health service (Bonnin 2014). In Extracts 1 and 2, R offers a series of diagnostic labels which are not developed, but dismissed by the professional. (See appendix for transcription conventions.)

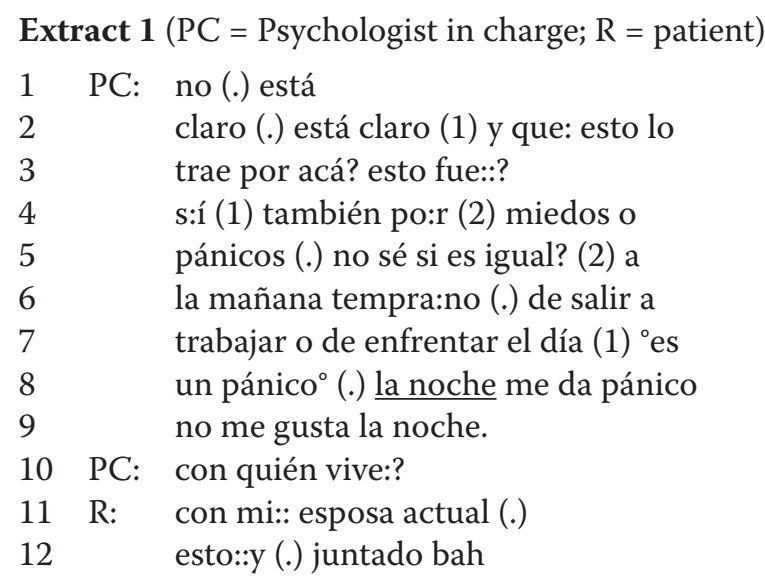

\section{Translation}

$\begin{array}{lll}1 & \text { PC: } & \text { no (.) it's } \\ 2 & & \text { clear (.) it's clear (1) so wh: this } \\ 3 & & \text { brings you here? this::? } \\ 4 & \text { R: } & \text { ye:ah (1) also becau:se (2) fears or } \\ 5 & & \text { panic (.) I don't know if it's the same? (2) early } \\ 6 & & \text { in the mo:rning, going out } \\ 7 & & \text { to work (.) or facing the day (.) }{ }^{\circ} \text { it's } \\ 8 & & \text { such a panic }{ }^{\circ}(.) \text { the night makes me panic } \\ 9 & & \text { I don't like night time } \\ 10 & \text { PC: } & \text { Who do you li:ve with? } \\ 11 & \text { R: } & \text { with my: current wife (.) } \\ 12 & & \text { I:: am (.) cohabiting, bah }\end{array}$

Extract $2(\mathrm{PC}=$ Psychologist in charge; $\mathrm{R}=$ patient $)$

1 PC: bueno (.) entonces eh: el motivo

2 por el que lo derivaron acá es su

3 estado de ánimo? podría decirse? lo

4 derivó un médico (.) dijo

5 R: sí: (.5) la ansieda:d (.3) este: (.)

6 depresión o:: no sé qué podría

7 llamarlo (.) [a veces]

9 PC: [desde cuándo?]

10 R: P2: bueno a vece:s (.) a vece:s me

11 acuesto no? y es como que no quiero

12 levanta:rme (1.3) este:: (.) a veces me

13 siento vací:o (.) tengo: (.) un par

14 de amigos pero nunca me vienen a ver.

15 estoy solo . no? está mi esposa al

16 lado pero no es lo mismo (.5) ${ }^{\circ} \mathrm{mi}$ esposa

17 que:: digamos (.) nos llevamos mas o

18 menos $^{\circ}$

19 PC: y desde cuándo usted tiene este: estado así que me cuenta? esta cuestión de los pensamie:ntos (.4) esta nosta:lgia?

\section{Translation}

1 PC: well (.) then eh: the reason

2 why you were referred here was your

3 mood? could we say? you were

$4 \quad$ referred by a doctor(.) you said

5 R: yes: (.5) anxie::ty, ehrm::: (.)

6 depression or:: I don't know what to

$7 \quad$ call it (.) [sometimes]

9 PC: [since when?]

10 R: P2: well some ti:mes (.) some ti:mes I

11 go to bed right? and it's like I don't want

12 to ge:t up (1.3) ehrm::(.) some times I

13 feel em:pty (.) I've got: (.) a few

14 friends but they never come to see me.

15 I'm alone, right? . my wife is with

16 me but it's not the same (.5) ${ }^{\circ}$ my wife

17 who:: let's say (.) we are not on very good

18 terms $^{\circ}$

19 PC: and since when have you had this:

20

mood you're telling me about? this

thing about thou:ghts (.4) this nosta:lgia?

In both extracts, there is explicit metalinguistic activity carried out by the patient (Extract 1, lines 4-5; Extract 2, lines 5-7) and the professional (Extract 2, lines 2-3). In Extract 1, the patient asks a question to introduce the technical term 'panic' ('pánico') (which leads to the diagnosis of 'panic attack', which has been widely discussed 
by mass media in Argentina). Having had previous experience in mental health interviews, $R$ avoids the direct use of diagnostic terms, which can be resisted by doctors (as shown by Broom 2005). Rather, in lines $4-5$ he tries to establish a terminological agreement on the synonymy of the non-technical 'fear' ('miedo') and the technical 'panic' ('pánico'). As the two-second pause is not filled by the professional, $\mathrm{R}$ continues with the description of the symptoms and now uses the term 'panic' without further justification: 'it's such a panic' (lines 7-8), 'the night makes me panic' (line 8). The professional, however, does not give any feedback regarding the metalinguistic question. On the contrary, when she takes the turn in line 10, she continues asking the demographic questions in the standard form and ignores the patient's attempt of self-diagnosis.

In Extract 2, PC offers a gist formulation (Heritage and Watson 1979), which deletes technical terms and in line 3 proposes a general category: 'mood' ('estado de ánimo'), as emergent of the 'voice of the lifeworld' (Mishler 1984). The patient does not seem to be comfortable with this commonsense formulation of his 'panic' and offers, in lines 5-6, technical alternatives: 'anxiety' ('ansiedad') and 'depression' ('depresión'). As in Extract 1, R proposes an indirect question on the appropriateness of both terms - as he did before, establishing the synonymy of 'fear' and 'panic'. This refusal to adopt the professional's formulations seeks a clinical interpretation of his 'mood'. However, the professional attempts to dismiss his self-diagnosis and to propose alternative, nontechnical terms, and therefore does not provide any feedback to the patient's attempts at diagnosis. On the contrary, PC rephrases 'mood' ('estado de ánimo', line 3) as 'this mood you're telling me about' ('este estado así que me cuenta', line 20). Although she presents this last term as indirect speech of the patient's prior interventions - 'you're telling $m e$ ' ('me cuenta'), she is actually referring to her own words in line 3 . Then, the technical terms 'anxiety' and 'depression' now become 'this thing about thoughts, this nostalgia' ('esta cuestión de los pensamientos, esta nostalgia', lines 21-22). Although she dismisses both terms in the interaction with the patient, later on she will diagnose him exactly in these terms.
In other interviews, the same professional explicitly rejects patients' self-diagnosis of panic attack. This can be seen in Extract 3, involving patient $\mathrm{V}$.

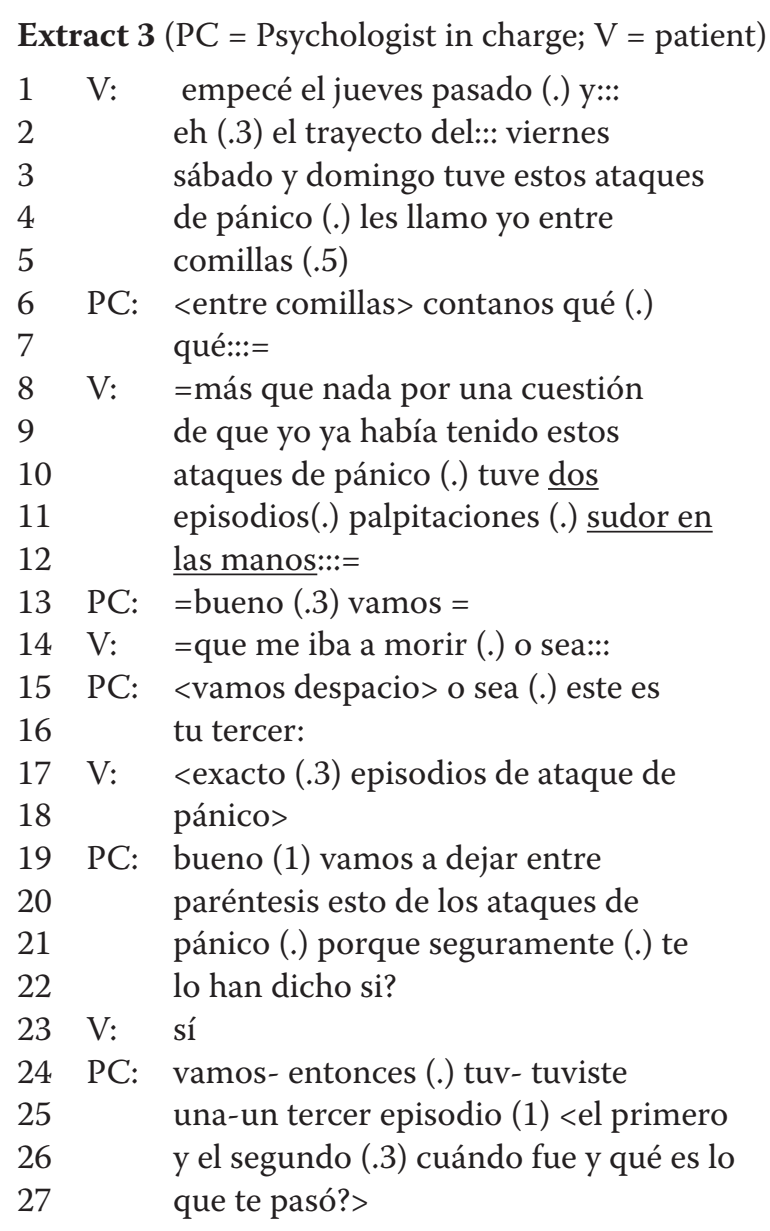

\section{Translation}

1 V: I started last Thursday (.) and:::

2 eh (.3) the time from::: Friday

3 Saturday and Sunday I had these panic

$4 \quad$ attacks (.) as I call them in quotation

5 marks (.5)

6 PC: <quotation marks > tell us what (.)

7 what:::=

$8 \mathrm{~V}: \quad=$ more than anything because I

9 already have had these

10 panic attacks (.) I had two

11 episodes (.) palpitations (.) sweaty

12 hands::: $=$

13 PC: =well (.3) let's =

$14 \mathrm{~V}:$ =like I was gonna die (.) like:::

15 PC: <take it easy> so (.) this is

16 your third:

17 V: <exactly (.3) panic attack

18 episode $>$ 
The extract begins, like the former two, with a metalinguistic reference to the technical term 'panic attack'. The hedge 'in quotation marks' ('entre comillas', lines 4-5) is repeated by the professional in line 6 , who echoes the hedge and not the expression hedged. Interpreting this as a confirmation, the patient begins to use the term as a diagnostic label, justified in lines 11-12 by the enumeration of symptoms and reinforced with the technical descriptive term 'episode' ('episodio'). In lines 15-16, the professional offers a new formulation to summarize the symptoms and elides the diagnostic term, which is again uttered by the patient: 'panic attack episodes' ('episodios de ataque de pánico', lines 17-18). Here is where the professional explicitly discredits self-diagnosis, discarding it as a non-qualified rumor (Anderson et al. 2003). To confirm the non-diagnosis, the professional repeats the expression with no qualifications: 'a third episode' ('un tercer episodio', line 25).

In sum, in this section we have observed how $\mathrm{R}$ (and also other patients, as seen in Extract 3) having some experience with mental health discourse and terminology, already has a series of technical terms which he offers to the professional to obtain - or confirm - a diagnosis. Patients do not claim technical or theoretical knowledge, but rather seem to use diagnostic labels loosely, as a means of collaborating with the professional in order to enhance the description of their symptoms. ${ }^{4}$ However, the psychoanalyst refuses to confirm it, either by implicitly avoiding feedback (Extracts 1 and 2) or explicitly rejecting it (Extract 3). In exchange, PC offers only common sense, lay terminology, referring to 'mood' ('estado de ánimo'), 'nostalgia' ('nostalgia') or 'episodes' ('episodio') with no qualifications.

\subsection{Offering treatment}

Right after the history-taking, and having avoided any diagnostic label, as seen in the previous section, R's analyst changes the subject abruptly with an offer of psychotherapy, as seen in Extract 4.

Extract $4(\mathrm{PC}=$ Psychologist in charge; $\mathrm{R}=$ patient $)$

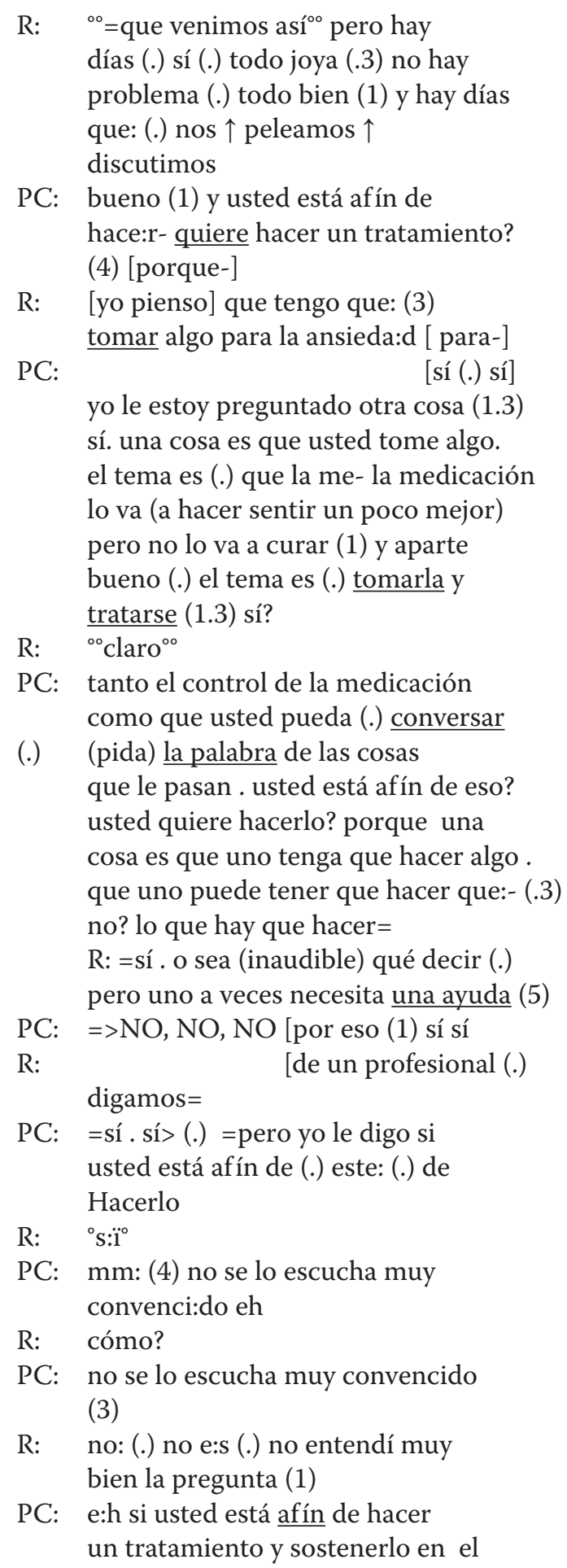




\section{Translation}

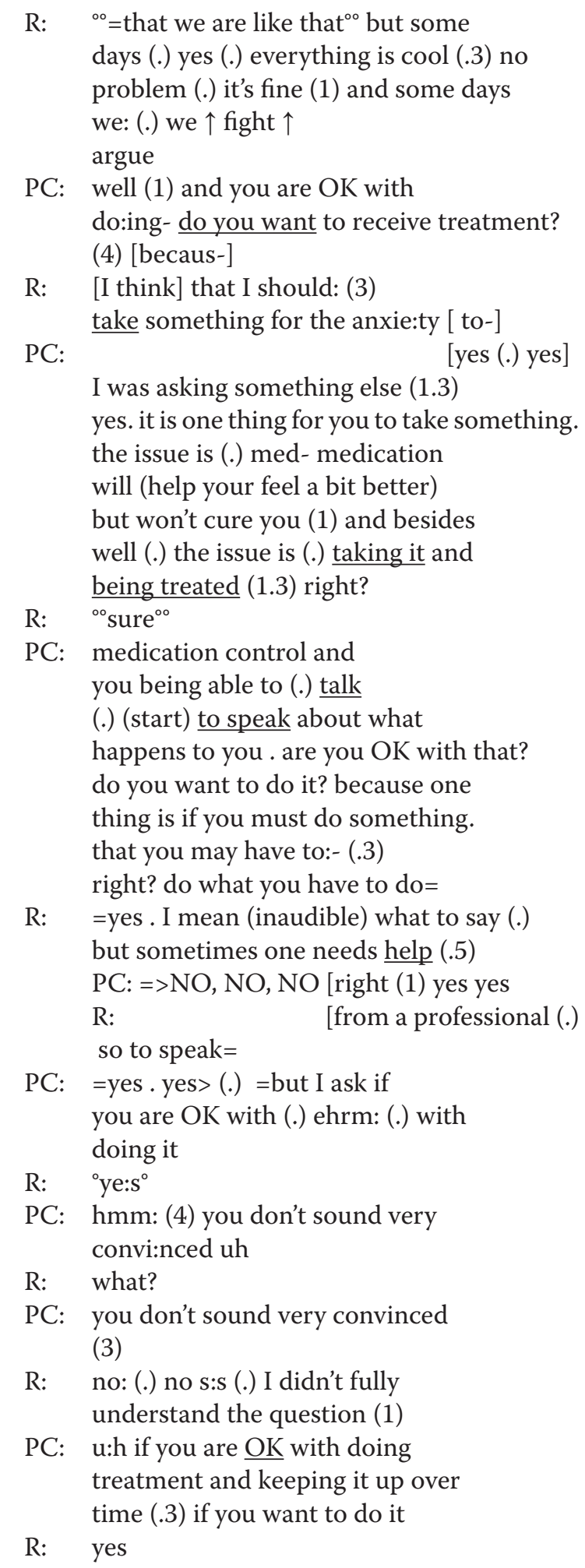

49 PC: oh, because I was saying that

50 you didn't sound very convinced (1.3)

51 R: yes (I want to do it)

The subject change begins with a 'well' ('bueno', line 6) and addresses the patient to offer him psychotherapy. As PC later explains, and can be seen in lines 38-39, 41 and 49-50, she thinks the patient is reluctant to undergo treatment; therefore, she rephrases 'to be OK with' ('estar afín', line 6,) as 'to want to receive treatment' ('querer hacer un tratamiento', line 7), thus attributing to $\mathrm{R}$ a more active role as subject of will. The expression, however, does not seem to be clear to R, who does not take his turn in the long four-second pause (line 8). The brief overlap in lines 10-11 leads to R's own proposal, also materialized through a mental process: 'I think that I should take something' ('yo pienso que tengo que tomar algo'). His rephrasing of 'treatment' as 'taking medication' is quite different from the analyst's offer of 'conversation'. As the analyst did not give him any chance to participate in diagnosis, this resistance seems to be a claim for his own voice (as seen by Koenig 2011).

Also, beyond the 'empowerment' feature of the patient's rephrasing, there is still a key misunderstanding which does not seem to be solved throughout the interaction: what is the analyst offering? The patient attempts to obtain psychiatric treatment at line 10 , repeating the term 'anxiety' ('ansiedad'), which worked as a tentative diagnostic label in Extract 2 (line 5). Refused by the analyst in lines 14-18, the patient attempts an upshot formulation (Heritage and Watson 1979), drawing the conclusion 'one needs help' ('uno [...] necesita una ayuda' line 29). This conclusion is also rejected (line 30) until the patient completes 'of a professional' ('de un profesional', line 31), which is confirmed in the same overlap (line 30). As $R$ requests help and the analyst requests his engagement, the repetition in lines 34-36 of the same question as in lines 6-7 does not clarify the topic. On the contrary, the patient offered two formulations which were plainly rejected. Therefore, his attempts at showing understanding of the offer have failed. The hesitation at line 37, the request for repair at line 40 , and the long pause at line 42 show 
this failure, which is explicitly formulated: ' $I$ did not fully understand the question' ('no entendi muy bien la pregunta', lines 43-44). However, the analyst in lines 45-46 repeats once again the question asked in lines 6-7, even using the same processes: 'to be OK with' ('estar afín') and 'to want to receive' ('querer hacer'). The laconic, straight answers in lines 48 and 51 seem to be just an exit, a way to answer affirmatively and close the interaction. In fact, $\mathrm{R}$ did not show up at his first psychotherapy session.

This example is quite different from other experiences - led by the same professional - in which she assumed a more sympathetic position toward the patient. In the case of J, who was later on to be diagnosed with somatic disorder with impairment of speech, the analyst assumes a pedagogical stance. As a consequence, in Extract 5 she explains what kind of treatment she is offering and is more careful in following the patient's reactions.

Extract 5 ( $\mathrm{PC}=$ Psychologist in charge; $\mathrm{J}=$ patient $)$

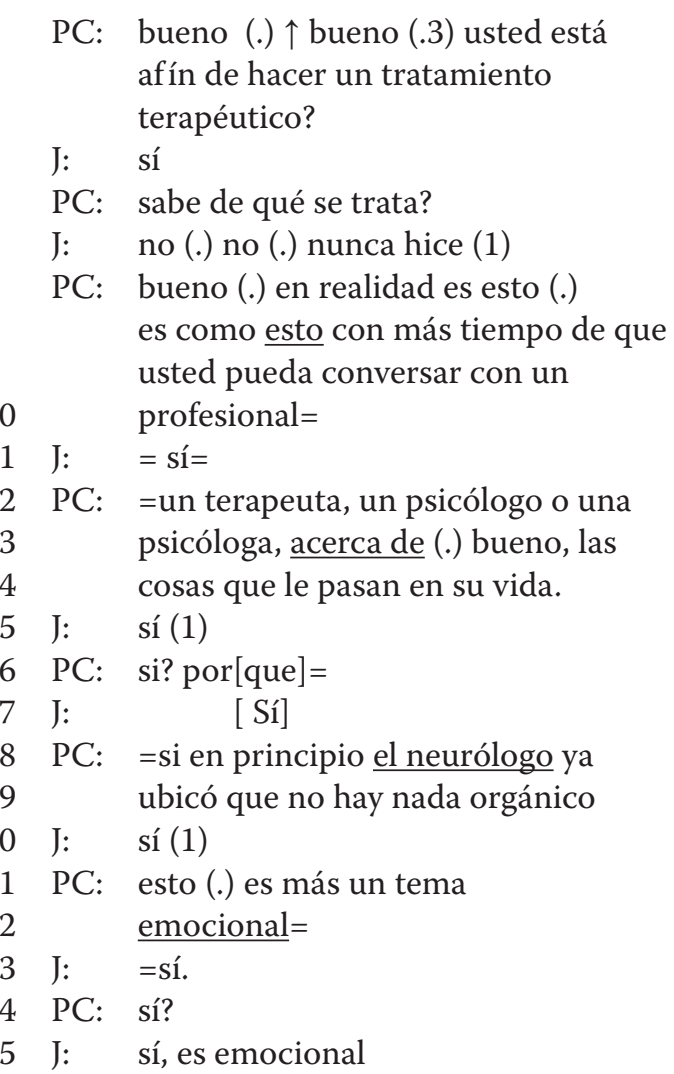

\section{Translation}

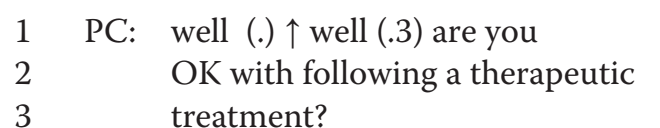

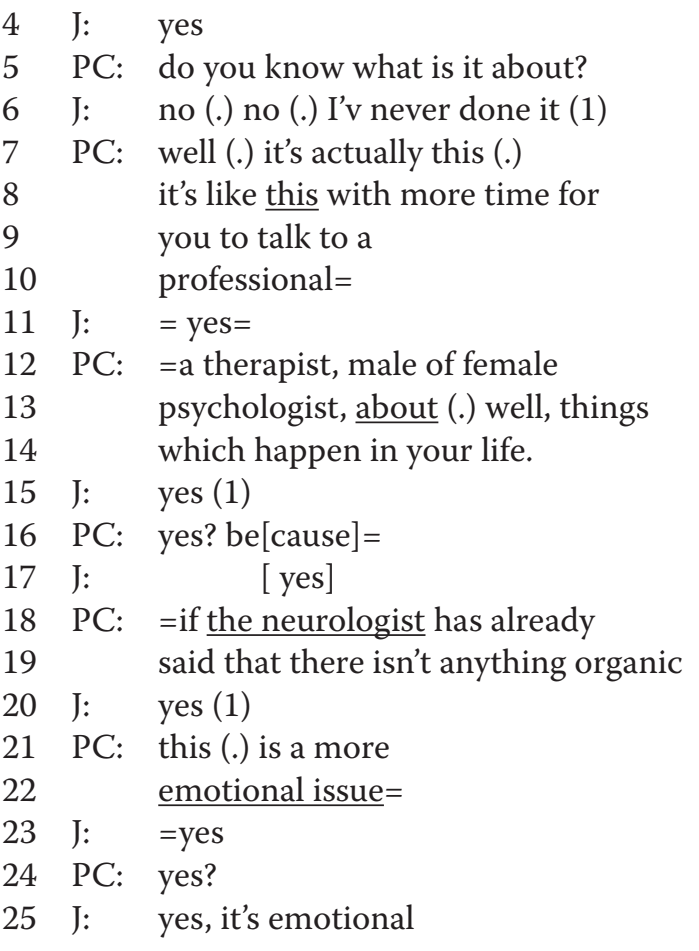

Because of the mild speech impairment declared - and shown - by J during the interview, the analyst not only explains what 'therapeutic treatment' ('tratamiento terapéutico', lines 2-3) is, but also even constantly seeks confirmations of her explanations. This strategy is useful, as seen in the first four lines of Extract 5: the affirmative answer in line 4 does not imply an understanding of the terms of the question. This is the same problem that we saw in Extract 4. However, instead of extending the misunderstanding for eighteen lines, here the analyst asks immediately for a confirmation (line 5) and, receiving a negative answer (line 6), develops a repair which expands the information. Although J confirms constantly with 'yes' ('sí') at lines 4, $11,15,17$ and 20, the analyst asks her again in lines 16 and 24, remembering that 'yes' does not necessarily mean that the patient understood the question. Then, in line 25 , J repeats the formulation of line 22, showing that she is following the analyst's reasoning and that she acknowledges with her almost-diagnostic claim: 'it's emotional' ('es emocional', line 25). This is not far from the DSM-IV diagnosis produced by the analyst after the patient was gone: it is somatic.

In this example, in contrast to the previous one, the analyst changes her strategy toward 
the patient. Thus, she produces pedagogical discourse which includes a step-by-step development of what 'psychotherapy' is, and a diagnostic formulation of the symptoms presented by J: 'it's emotional. These two elements, explaining treatment and offering a tentative diagnosis, seemed to be enough to reassure the patient somewhat, and she is at the time of writing undergoing therapy at the hospital.

\section{Confronting psychoanalytic and medical discourses}

One of the motivations for this article was the perception of a contradiction in the way psychoanalysts relate to what they call the 'medical discourse', i.e. an order of discourse (in a sense close to Foucault 1969) which seeks regimentation and disciplining through biologization of subjects, including personality, behavior, cognition and psyche. I interpret this relationship as contradictory because, among many other reasons, the institutional place is itself a hospital which offers mental health just as it offers orthopedic surgery. Indeed, a few psychoanalysts in the service are also psychiatrists and perceive this relationship as, if not contradictory, at least difficult to reconcile (Lakoff 2006: 84-85).

Although members of the mental health service are aware of this tension, many patients are not. On the contrary, medical discourse is the only framework they have for understanding what happens at a hospital, no matter what medical specialty they use. Asking for a diagnosis ('what's wrong with me?'), and asking for medication to be treated ('what can I take?') are the expected actions in a doctor-patient interaction, as far as patients know. To Lacanian psychoanalysts, medication and diagnostic labeling are two characteristic features of medical discourse, and therefore to be resisted, as I pointed out in the first analytical section. Refusing diagnosis is, from their point of view, resisting the biologization of the psyche.

This practice is partially coherent with the psychoanalytic idea that patients are the ones who 'know' and professionals only 'guide' them to elicit this knowledge (Schafer 2005; Waska 2006), although this guidance is achieved through diagnostic formulations oriented toward institutional answers (Antaki et al. 2005; Bartesaghi 2009). In any case, patients' expectations in medical settings include a diagnosis, i.e. a proposal about their clinical condition (Maynard 2004). Instead, outpatients at first interviews do not receive a diagnosis but an offer of treatment, which is, in many cases, recommended unilaterally by the professional. Patients' self- or other-diagnoses, which fill the need for knowledge and can empower patients within their asymmetrical relationship with professionals (Broom 2005; Giles and Newbold 2011), are often dismissed by psychoanalysts. Indeed, instead of providing alternative formulations (Antaki et al. 2005) or other discursive strategies for diagnosing (Maynard 2004), nothing is offered but psychological treatment. In other words, patients are told that psychoanalysis 'cures with words' (Peräkylä et al. 2008) but they are not told what the problem is that should be cured. The asymmetrical relationship between participants disadvantages patients, who cannot argue about the treatment offered by the professional (as seen by Koenig 2011, for instance) but can only take it or leave it. As we have seen in the case of $R$, the patient leaves the hospital: even though he was explicitly admitted, he was communicatively rejected. However, this process can be different: the case of J shows that explaining psychoanalytical treatment and offering a tentative diagnostic label can be sufficient to provide feedback to the patient and encourage his/her adherence.

Resisting medical discourse in medical settings can therefore be contradictory, not only for analysts, but especially for patients who find it difficult to understand what is going on. Perhaps professionals could be more flexible towards patients' expectations about diagnosis and treatment as a way of ensuring access and adherence to mental health service. As seen in Extract 5, this strategy of negotiation with medical discourse can be successful in guaranteeing engagement and continuity in treatment. These questions to be addressed by professionals and patients warrant further research. 


\section{Appendix: Transcription conventions}

Adopted from Richards and Seedhouse (2005).

[

]

$=$

(.) underline

$:::$

$-$

?

!

,

indicates falling (final) intonation

CAPITALS especially loud sounds relative to surrounding talk

utterances between degree signs are noticeably quieter than surrounding talk

๑ ००

(guess)

indicates the point of overlap onset indicates the point of overlap termination

inserted at the end of one speaker's turn and at the beginning of the next speaker's adjacent turn, indicates that there is no gap at all between the two turns

an interval between utterances ( 3 seconds and 2 tenths in this case) a very short untimed pause indicates speaker emphasis indicates lengthening of the preceding sound

indicates an abrupt cut-off rising intonation, not necessarily a question an animated or emphatic tone indicates low-rising intonation, suggesting continuation considerably quieter than surrounding talk comments on non-linguistic behavior

indicates transcriber doubt about a word

\section{Notes}

1. This is a key difference with other studies, such as the valuable book by Telles Ribeiro (1994), which analyzes the admission process of an inpatient to a psychiatric institution.

2. In my three years of observation, I have never seen a case of a 'perverse' patient.

3. As a consequence, these statistics are not accurate at all. During 2008, 43\% of patients were diagnosed within the category of Dysfunctional Behavior Disorder; during 2009, only 1\% fell into this category. In contrast, $44 \%$ of the patients were diagnosed as Mental Disorder Not Otherwise Specified, which represented $11 \%$ in 2008. A sudden change in the demography of mental health being highly unlikely, the most probable interpretation is that there was a sudden change in the use of default diagnostic categories.

4. I owe this observation to one of the anonymous referees of this article, who accurately pointed out that some technical terms are a part of social discourse in general. As a consequence, patients adopt them 'in the service of communicating efficiently with a health care professional'. I have examined these strategies of communicative accommodation elsewhere (Bonnin 2014).

\section{References}

American Psychiatric Association. (1994) Diagnostic and Statistical Manual of Mental Disorders. Fourth edition. Washington, DC: APA.

Anderson, J., Rainey, M. and Eysenbach, G. (2003) The impact of cyberhealthcare on the physicianpatient relationship. Journal of Medical Systems 27 (1): 67-84. http://dx.doi.org/10.1023/A:102 1061229743

Antaki, C., Barnes, R. and Leudar, I. (2005) Diagnostic formulations in psychotherapy. Discourse Studies 7 (6): 627-647.http://dx.doi.org/10.1177/146144 5605055420

Arnoux, E. B. N. (2006) Análisis del Discurso: Modos de abordar materiales de archivo [Discourse Analysis: Ways for Approaching Archive Materials]. Buenos Aires: Santiago Arcos.

Balán, J. (1992) Cuéntame tu vida: Una biografía colectiva del psicoanálisis argentino [Tell Me About You: A Collective Biography of Argentinean Psychoanalysis]. Buenos Aires: Planeta.

Bartesaghi, M. (2009) Conversation and psychotherapy: How questioning reveals institutional answers. Discourse Studies 11 (2): 153-177. http:// dx.doi.org/10.1177/1461445608100942

Blommaert, J. (2005) Discourse: A Critical Introduction. Cambridge: Cambridge University Press. http://dx.doi.org/10.1017/CBO9780511610295

Bolívar, A. (2010) A change in focus: From texts in contexts to people in events. Journal of Multicultural Discourses 5 (3): 213-225. http://dx.doi.org/ 10.1080/17447141003602312

Bonnin, J. E. (2013) The public, the private and the intimate in doctor-patient communication: Admission interviews at an outpatient mental 
health care service. Discourse Studies 15 (6): 687-711. http://dx.doi.org/10.1177/1461445613 492249

Bonnin, J. E. (2014) Expanded answers to bureaucratic questions: Negotiating access to public healthcare. Journal of Sociolinguistics 18 (5): 685-707. http://dx.doi.org/10.1111/josl.12093

Broom, A. (2005) Virtually he@lthy: The impact of internet use on disease experience and the doctor-patient relationship. Qualitative Health Research 15 (3): 325-345. http://dx.doi.org/10. $1177 / 1049732304272916$

Crowe, M. (2000) Constructing normality: A discourse analysis of the DSM-IV. Journal of Psychiatric and Mental Health Nursing 7 (1): 69-77. http://dx.doi.org/10.1046/j.1365-2850.2000. 00261.x

Foucault, M. (1969) L'Archéologie du savoir [The Archaeology of Knowledge]. Paris: Gallimard.

Garand, L., Lingler, J., Conner, K. and Dew, M. (2009) Diagnostic labels, stigma, and participation in research related to dementia and mild cognitive impairment. Research in Gerontological Nursing 2 (2): 112-121. http://dx.doi.org/10.3928/194049 21-20090401-04

Giles, D. and Newbold, J. (2011) Self- and otherdiagnosis in user-led mental health online communities. Qualitative Health Research 21 (3): 419-428. http://dx.doi.org/10.1177/10497323 10381388

Heritage, J. and Maynard, D. (eds) (2006) Communication in Medical Care: Interaction between Primary Health Care Physicians and Patients. Cambridge: Cambridge University Press. http:// dx.doi.org/10.1017/CBO9780511607172

Heritage, J. C. and Watson, D. R. (1979) Formulations as conversational objects. In G. Psathas (ed.) Everyday Language: Studies in Ethnomethodology, 123-162. New York: Irvington.

Koenig, C. (2011) Patient resistance as agency in treatment decisions. Social Science \& Medicine 72 (7): 1105-1114. http://dx.doi.org/10.1016/j. socscimed.2011.02.010

Lakoff, A. (2003) The Lacan ward: Pharmacology and subjectivity in Buenos Aires. Social Analysis 47 (2): 82-101. http://dx.doi.org/10.3167/01559770 3782352970

Lakoff, A. (2006) Pharmaceutical Reason: Knowledge and Value in Global Psychiatry. Cambridge: Cambridge University Press.

Macchioli, F. (2012) Inicios de la terapia familiar en la Argentina. 1960-1979 [Beginnings of family therapy in Argentina. 1960-1979]. Estudos e pesquisas em psicologia 12 (1): 274-287.
Maynard, D. (2004) On predicating a diagnosis as an attribute of a person. Discourse Studies 6 (1): 53-76. http://dx.doi.org/10.1177/146144560 4039439

Mishler, E. G. (1984) The Discourse of Medicine: Dialectics of Medical Interviews. Norwood, NJ: Ablex.

Peräkyla, A., Antaki, C., Vehilläinen, S. and Leudar, I. (2008) Analysing psychotherapy in practice. In A. Peräkyla, C. Antaki, S. Vehilläinen and I. Leudar (eds) Conversation Analysis and Psychotherapy, 5-25. Cambridge: Cambridge University Press.

Plotkin, M. (2001) Freud in the Pampas: The Emergence and Development of a Psychoanalytic Culture in Argentina. Stanford, CA: Stanford University Press.

Richards, K. and Seedhouse, P. (2005) Applying Conversation Analysis. Basingstoke, UK: Palgrave Macmillan.

Rubistein, A. (1999) Algunas cuestiones relativas al diagnóstico en psicoanálisis [Some issues regarding diagnosis in psychoanalysis]. Revista de psicoanálisis 1: 119-127.

Schafer, R. (2005) Listening in psychoanalysis. Narrative 3 (3): 272-280.

Telles Ribeiro, B. (1994) Coherence in Psychotic Discourse. Oxford: Oxford University Press.

Thompson, S., Frydman, A., Salinas, L., Mantegazza, R., Toro, C. and Lombardi, G. (2006) El proceso diagnóstico en psicoanálisis [Diagnostic process in psychoanalysis]. Anuario de Investigaciones 14: 103-110.

Waska, R. (2006) Psychoanalysis or psychoanalytic psychotherapy? Shifting the debate from theoretical to clinical with the concept of analytic contact. Bulletin of the Menninger Clinic 70 (2): 145-159. http://dx.doi.org/10.1521/bumc.2006.70.2.145

World Health Organization (1999) International Classification of Diseases. Geneva: WHO.

Juan Eduardo Bonnin teaches Semiotics at the University of Moreno and the University of San Martín and is a Researcher at the Consejo Nacional de Investigaciones Científicas y Técnicas. His interests include interdisciplinary research on language, inequality, and access to civil rights, especially in the field of healthcare. His latest published book is Discurso religioso y discurso político en América Latina. Leyendo los borradores de Medellín (1968) (Buenos Aires, Santiago Arcos, 2013). Address for correspondence: Balbastro 886, CP: 1424, Buenos Aires, Argentina. Email: juaneduardobonnin@yahoo.com.ar 